\title{
The methodological involvement of the emotional design and cognitive ergonomics as a tool in the development of children products
}

\author{
Walter Correia ${ }^{\text {a, }}$, Laís Rodrigues ${ }^{\text {a }}$, Fábio Campos ${ }^{\text {a }}$, Marcelo Soares ${ }^{\text {a }}$, Marina Barros ${ }^{\text {a }}$ \\ ${ }^{a}$ Design Department, CAC, Universidade Federal de Pernambuco, Av. dos Reitores, S/N, Recife-PE, Brazil
}

\begin{abstract}
To demonstrate the relationship between design and emotional development for kids, this article offers an initial approach about the definition and historical aspects of emotion in product development, citing the main authors of this issue. Based the field research conducted with children from 2 to 6 years of age, was also describes the basic ideas of Piaget in the child psychology and pre-operational stage (age group studied) and the significance of children's toys from the perspective of Vigostsky. Using this theoretical framework and results of field research, we can infer some emotional design as advocated by the producers of positive affect on humans and its relationship with the child's development and choices of their toys.
\end{abstract}

Keywords: Emotion design, development of children, infant toys

*Corresponding author. E-mail: ergonomia@terra.com.br- 


\section{Introduction}

The act of playing and having fun are very important for child development, and the toy is the most important link of this link. The creation of a toy can be an enriching and rewarding, as the developer becomes the interpreter of the desires, curiosities and needs of small consumers. In play, the small express their concerns, their way to see the world around them and, especially, acquire new knowledge, skills, and thoughts.

But then, as a toy instill in all these meanings? How to combine playfulness and learning in a really attractive toy for kids? For John Matta, professor of marketing to children of ESPM Sao Paulo in an interview with River Media, says that a child passes through various stages ranging from birth to 12 years of age. During the early years prior to adolescence, which reigns in your life are the emotions. In addition to the emotional needs of supply mentioned above, it is the responsibility of companies that sell children's products also concern themselves with the social needs of children: motor development, cultural, educational, ethical and, especially, emotional [9]. It is observed then, that children do not choose your material universe only by form or function, like many adults, but also the meaning that the object provides. As a tool for allocation of these meanings, has stood out ever more emotional design.

Through the study of aesthetic experiences, decision-making, subject-object relationship, brain levels and the mediation of culture projectual design, emotional design can be an important ally of the developers of toys. [7] argues that the emotional element of an object can be more critical to your success than the cognitive element. Positive emotions cause the child to think creatively, finding solutions to problems more easily encountered during the interaction with the object. [2] states that every object that excites an instant, also excites an emotion. Pain and pleasure are the levers that the body needs so that strategies acquired and instinctive act effectively. Childhood is a period of rapid physical and mental development and intense, the importance of emotional experiences for the healthy development of children should not be overlooked.

One sees then that the integration of the study of emotions is an important aspect to be considered in building a culture projectual, providing new methods of research to develop products more user-centered. Especially in the early stages of life, where the object is to be attractive to the child when the emotional aspects are present pleasurable, motivating them to learn and use to overcome the difficulties you encounter. The emotion in aesthetic experience in children is a means to distinguish the properties that an object has and expresses. Through the use of cognitive, the child discriminates and emotions related to assess and grasp the object, integrating them into their new experiences of a vast world to be discovered.

This article aims to demonstrate the importance of the relationship between child development and emotional design in the manufacture of toys intended for that audience. To this end, we seek to develop a field research with children aged 2 to 6 years of age, analyzing some aspects emotional design as advocated by the producers of positive affect in humans.

\section{Conceptualizing emotional design}

For science, emotions change the perception, behavior and thinking through the parameters of neuroactive chemicals that penetrate certain brain centers. For us humans, these emotions turn out to be a guide for most decision-making that we are subjected to every day, mainly in the choice of the material world around us. A product may please or displease us, depending on the previous memories we have of him, or just by our mood when we are confronted with this product. According to [7] a favorite object is a symbol that ends in inducing positive feelings through our memories, which in turn makes an individual expression of each one of us.

This issue is gaining more space in the strategies of product differentiation applied to the design. [6] state that the user has an affectionate relationship with the product that consumes, with the designer, as its primary function, trigger positive feelings in consumers, providing a pleasant experience in the use of the product and thus establishing a more intimate relationship between artifacts and industrial users.

Moraes (2008) and cited in [6] considers the inclusion of an emotional factor human factor, giving the product the property to meet the aspirations qualitative as fantasy and ideology, now recognized as important in the design.

[7] argues that results are three different levels of brain structure: the visceral level - automatic and preprogrammed responsible for quick judgments, the behavioral level - which refers to brain processes that control most of our actions and the level reflective - 
it is the contemplative part of the brain, on the interpretation, understanding and reasoning. These three levels always operate together in our relationship with the objects present in our environment, being responsible for the design visceral impact with the first product, the design behavior related to functional aspects of the design artifact and reflective on the subjective interpretations and personal with for the product.

It is clear here that the emotional design is not just an activity related aesthetic or functional factors, however, this new branch of the search include the design aesthetic and functional factors adding to them another extremely important factor: the symbolism. It is necessary that the designer is always aware of the impact that your product will have on society. This is not easy to predict, but problematic factors between the human-product can be analyzed and mitigated in order to make this exchange more positive. The psychologist Isen (1993) cited in [7, p.39] argue that being happy broadens the thought processes and facilitates creative thinking. The aesthetically pleasing objects make people feel better and this makes the solution to some problems related to products is achieved more creatively.

\subsection{Aspects of cognitive reasoning}

It is important to note here the distinction between needs and wants. The need is older and is responsible for everything necessary for our survival, since the will is a concept more related to culture that we have contact, so influenced by advertising or our expectations regarding our self-image, hence its extreme connection with the reflexive level.

The behavioral and reflective levels are the ones who are subject to change and / or adapted according to culture and education we have. The level is less visceral changes, since this was already present in ancient times of our civilization, even if unconsciously, for example, in search of warm clothes for cold or afraid to approach the fire to know that we could the burn.

However, all these mechanisms with reputable biologically pre-programmed predispositions are just, and not absolute truths that must be triggered by experiences. [2] states that we exist and then to the extent that we think exist, since the thought is caused by studies and operations of a being. [10] also says that emotions are preceded by sensations, coming just after someone get some kind of stimulus, then causing a sensation.
It is necessary to remember that despite all these aspects common to human beings, each person has specific characteristics and unique combinations of preferences, the designer needs to study this set of standard features and relate these to the elements of individual differences of the target audience to which designed your product in order to make it closer to its customers, which is not an easy task.

\section{Basic ideas for second child psychology of Piaget}

According to [1] the focus of Piaget's studies related to child psychology was the development of cognitive structures, development patterns that are common to all children and not the intellectual power or individual differences of each. Thus, Piaget established three important points and balancing psychic reorganization, which resulted in a division for all four stages of child development: the sensorimotor, ranging from birth to 2 years of life, the pre-operational, the 2 to 6 years, the concrete operational, 6 years to 12 years of age and formal operational, which starts from 12 years of life.

For [8] the cognitive development of children invariably follows this sequence, although the ages at which they reach a certain stage may vary according to their intelligence or with the social environment in which they live. For him the main factors in the child's cognitive development is the interaction between maturity, experience, social relations and balancing, which is the relationship between assimilation and accommodation, that is, how external factors interact with cognitive development staff. It is always important to add here also the biological factors and individual pace of each child.

[12] also noted that Piaget's theories do not bother to study how concepts develop and how to develop concepts. Your acceptance is linked, generally, its usefulness to predict children's behavior, his persuasive power and his logic offering an alternative to understand the behavior and development of children up to the present day. However, like any other theory in psychology, Piagetian theory is continually being validated, tested and repackaged, according to new studies.

\subsection{The perspective of Piaget's pre-operational stage}

According to [1] pre-operational stage that will, according to Piaget, from 2 to 6 years of age is a stage where the use of symbols is extremely evident, 
representation and "make-account" is always present in their play, which will have great participation in the emergence and development of language. But sensory-motor schemes are not wealthy or forgotten, by contrast, are more refined, the child can perform more complex movements than the previous phase.

According to Piagetian theory change schemes simple sensory-motor stage of infancy to the first schemes of this stage is given by three basic processes: assimilation, accommodation and balance (or imbalance, as the author). Assimilation is the process of data entry schemes already structured in the infant brain; accommodation to modify or create other schemes brain due to the introduction of new and different concepts and balancing the actual realization of one of the earlier cases, namely the point equilibrium between assimilation and accommodation.

This is the stage where the relationship with the material world that surrounds it becomes even more important for their cognitive development. The focus of pre-school in the appearance of objects is a very important point in describing this stage Piaget about being present in their most famous conservation studies.

More recent views of thought pre-school children say at this stage of development are much less egocentric than Piaget thought, although there is still resistance as an understanding of appearance and reality. A child's mind at this age begin to understand that it can not predict what others will do, leaving only a note of the situation itself, their desires and beliefs have also entered into the equation. This shows a much closer relationship between their emotions, the world and people around them.

\section{Regarded game, toy and play}

Game, toy and game are terms that confuse depending in essence, even the language used. In French, Portuguese and English these terms have different peculiarities and ways of use: In English and French words "play" and "play" have different meanings and can represent the action of playing, among other activities unrelated to represent the playful action, already in Portuguese the word "play" features an unstructured play activity and the word "play" activities with the use of specific rules. But even with this basic distinction in the English language these terms are often confused with each other, if necessary, often, a study regarding the sociocultural context in which these words are being used.
Since the action performed by the child in making the game can be considered fun, [4] considers the toy object support this action of "play", unlike some other authors who have the toy area as a cultural object, imbued with meanings and representations that take a playful social function, and thus the product of the society in which it operates. Authors such as by [3] further clarifies that the toy has a symbolic value that dominates its functional aspect, so the symbol is, therefore, the function of the object itself. Through symbolism, a child can easily turn a broom into a horse, which quickly illustrates the issue of symbolism and function on the objects.

[10] argues that play, even free and unstructured, has inherent rules. To play him in all kinds are built into the rules, even in make-believe, where a girl plays to be the mother of her dolls, assumes behaviors and attitudes present in your universe of knowledge about the maternal figure. Taking into account the meaning as defined earlier game, you can then think that all play for [10], is considered a game, but in the game, there is the presence of an object to be achieved often end: victory.

Usually these rules have a deep connection with the social and cultural universe in which the child is present and arrive ready for these small, the advantage is that even getting ready, usually the children are free to modify or simply ignore them depending on the context in which the game runs. Making the child has the pleasure to "play by play," regardless of the victory, but the process, the game ends with an end in itself.

It can be seen then play and play, containing an end in itself end up being indistinguishable, hence the confusion between these terms. The definition and design of these actions depend largely on the perspective used by the author who chooses to work, their studies and research, and especially the influence that society and culture play in this game worldwide in which children are embedded. You also need a thorough research about the characteristics and influences the behavior and child development in relation to play.

\section{Vigostsky in action and significance of the toy}

[10] questions the sense of pleasure to the toy, given that the relationship toy / pleasure is not straightforward, because the toy does not always provide pleasure to the child. He emphasizes the need for children to experience many stimuli (motives, trends and incentives) during its development, while 
the super critical appreciation of the cognitive domain and affective before the engines and do understand the importance of wonder toy from a global perspective.

Children in preschool, desire, satisfaction and immediacy connected to the imagination, are integral components of a toy, which alone and isolated from other elements, can be considered as an imagination without action, just the toys are created from a motivation generated by an imaginary situation [10].

For the author above the child object is the dominant factor because the object / meaning and significance is subject to the object, the toy has the meaning becomes the central point in the relationship and the objects are moved to a subordinate position, thus the transient nature of the toy consists of a stage in which the purely situational constraints of early childhood and adult thought can be completely disrupted the real situations.

\section{Field research}

It is known that the aesthetic features of a product they have some influence on our emotions and how to act. Children, for example, stimulate expression and many of his feelings through the use of color, attributing positive characteristics to the bright colors and dark negative the other. [3] also claims that 3D textures present in some artifacts can contribute to improving the emotional relationship between consumers and products, especially among children under age.

Verifying the claims defended in this study, this research aims to be a tool to help professionals in the creation of articles focused on children, causing them to participate more actively in the child's emotional universe, identifying feelings more easily to the common range group studied. Can then develop toys and children's products effectively closer to the target audience they are aimed at these articles.

\subsection{Methodology}

Based on these statements, as well as all the research done on the theoretical literature, this research field is to demonstrate the behavioral character of the claim defended in the article about the relationship between the use of emotional design in the development of his toys and well accepted by these small users.
To this end, research will be divided into three phases (one visit per day), which will be presented with 60 randomly chosen children (30 children aged between 2 and 6 years of a public school in the city of Arcoverde interior of Pernambuco, and 30 children the same age of a private school in the city of Caruaru, Pernambuco interior also) different aesthetic characteristics related to the product such as color, shape and texture, among the options to be chosen by the children are also those that are advocated by Norman as booster of positive affect on the product. The goal, therefore, is to verify if these features will actually be chosen by the children.

In the first phase of research will be presented to party balloons with the three primary colors of rose color (blue, red and yellow) for each child to choose only one they like best. The intent in this first part of the research is to discover and report what color it has more positive emotional affinity with children.

Having at hand the result of the first phase, it can be applied in three basic geometric shapes (triangle, square and circle) and an amorphous (shapeless set) the color chosen by the children earlier. This phase will take place with the same 60 children, just observing what form more positively influence them. Importantly, the main intention at this stage is that the color variation does not influence the results of choice of form, so the application the application of color in selected earlier forms of this second phase of the research.

Chosen the color and shape by children, these defined, finally, the texture more emotional part of his universe, with the options surfaces: rough, polished and plush. All choices in this phase will be reported and properly analyzed to obtain concrete results that will be added, finally, the results obtained in earlier phases of research.

\subsection{Results}

The analysis and tabulation of data from the three phases of research have proven that bright colors, organic shapes and sinuous, and smooth, shiny surfaces exert a strong influence on the choice of objects from the child. Importantly, according to the survey, despite having obtained a lower value than the glossy surface, the teddy was shown to have strong influence on the choices among the female population. The figures for these stages can be observed in Tables 1, 2 and 3. For purposes of understanding this paper uses $\mathrm{AC}$ and $\mathrm{TC}$ as Arcoverde City and Town of Caruaru respectively: 
Table 1 - Table of results of Phase 1 (Color)

\begin{tabular}{|l|l|l|l|l|}
\hline Color & AC & TC & Total & Percentage \\
\hline Red & 22 & 15 & 37 & $61,67 \%$ \\
\hline Blue & 04 & 06 & 13 & $21,67 \%$ \\
\hline Yellow & 04 & 09 & 10 & $16,66 \%$ \\
\hline
\end{tabular}

Table 2 - Table of results of Phase 2 (Shape/Form)

\begin{tabular}{|l|l|l|l|l|}
\hline Shape & AC & TC & Total & Percentage \\
\hline Sphere & 10 & 09 & 19 & $31,67 \%$ \\
\hline Cube & 01 & 03 & 04 & $6,67 \%$ \\
\hline Triangle & 02 & 03 & 05 & $8,33 \%$ \\
\hline Amorphous & 17 & 15 & 32 & $53,33 \%$ \\
\hline
\end{tabular}

Table 3 - Table of results of Phase 2 (Texture)

\begin{tabular}{|l|l|l|l|l|}
\hline Texture & AC & TC & Total & Percentage \\
\hline Glossy & 17 & 15 & 32 & $53,33 \%$ \\
\hline Plush & 13 & 13 & 26 & $43,33 \%$ \\
\hline Rough & -- & 02 & 02 & $3,34 \%$ \\
\hline
\end{tabular}

\section{Final}

Through all bibliographic studies so far analyzed, verified and confirmed in field research, we can infer that many aspects of emotional design as advocated by the producers of positive affect in humans, such as bright colors, organic forms and continuous and surfaces smooth and shiny, really relates to children's development and choices of the material world around them.

It is seen that children do not choose their toys just the way the function, how many developers think of children's items, but also the meaning that the object provides. This question can be easily observed in many of the jokes made by the small age group analyzed in the research field, due to the strong symbolism and the use of "make-believe", some toys used by children aged 2 to 6 years of age may not match what they actually are in reality, eg. a broom handle can turn into a horse used by the prince to save the princess if the children they wish.

Childhood is a period of rapid learning and intense emotional experiences in their toys are options that should not be overlooked. The emotional design aesthetic experience in children is a means to distinguish the properties that an object has and expresses, integrating it into their new experiences.

However, it is noteworthy that all these stimuli must be worked in order to learn and fun to be carried out effectively and efficiently. Hence the importance of emotional design in the development process of the toy, making the child the center of this whole process. Through studies and research in this area will be able to design effective educational toys for the age group it is intended, while making changes and cognitive prerequisites for a positive interaction with the child's toy.

\section{References}

[1] Bee, H. A Criança em desenvolvimento, $9^{\text {a }}$ Ed. Porto Alegre: Artmed, 2003.

[2] Damásio, A. O erro de Descartes São Paulo: Companhia das Letras, 1998.

[3] Kindlein TR., Wilson et al. A natureza como fonte de inspiração para a criação e desenvolvimento de texturas aplicadas ao design industrial. In: CBPDD. São Paulo: Fundação Armando Álvares Penteado, 2004.

[4] Kishimoto, T. M. O jogo e a educação infantil. São Paulo: Pioneira Thompson Learning, 2002.

[5] Matta, J. Entrevista ao site Rio Mídia. Marketing infantil: um importante novo campo de estudo. Disponível em: http://www.multirio.rj.gov.br. Acesso em: 20 de abril de 2008.

[6] Mont'Alvão, C.; Damazio, V. Design, ergonomia e emoção. Rio de Janeiro: Mauad X: FAPERJ, 2008.

[7] Norman, D. A. Design emocional: porque adoramos (ou detestamos os objetos do dia-a-dia). Tradução de Ana Deiró. Rio de Janeiro: Rocco, 2008.

[8] Piaget, J. Inhelder, B. A psicologia da criança, $2^{a}$ Ed. Rio de Janeiro: Difel, 2006.

[9] Rego, T. C. Vigostsky: uma perspectiva histórico-cultural da educação, 4 a Ed. Rio de Janeiro: Editora Vozes, 1995.

[10]Vygotsky, L. S. A formação social da mente: o desenvolvimento dos processos psicológicos superiores, $7^{\mathrm{a}} \mathrm{Ed}$. São Paulo: Martins Fontes, 2007.

[11]_. A psicologia da arte. São Paulo: Martins Fontes, 1999

[12] Wadsworth, B. J. Inteligência e afetividade da criança na teoria de Piaget, $3{ }^{\text {a }}$ Ed. São Paulo: Pioneira, 2003. 